\title{
Методы оценки влияния добычи золота и урана на экосистему
}

Мустафаев М.А., магистр, Намазов С.3., магистр, Навоийский государственный горный институт, 2. Навои, Узбекистан E-mail: u0505@mail.ru

Научный руководитель: к.т.н., доцент Музафаров А.М.

Горнодобывающая промышленность является одной из ведущих отраслей в Республике Узбекистан. По запасам ряда важнейших полезных ископаемых, таких, как золото и уран Республика Узбекистан входит в первую десятку государств мира.

Золото и уранодобывающие горно-металлургические производства в ходе своей деятельности наносят ущерб природному балансу экосистемы. Величина этой влияния на экосистему оценивается путем анализа проб почв, воздуха, производственных сточных и подземных вод [1, 2]. В среде загрязнителей экосистемы особое место занимают вредные, токсичные, радиоактивные загрязнители и их соединение в почве, воздухе, растениях, питьевых, производственных сточных и подземных водах [3-6].

В данной работе рассмотрены методы оценки влияния добычи золота и урана на экосистему.

Оценка техногенного влияния золотодобывающего производства на экосистему.

Как многих странах мира, в Узбекистане добыча золотосодержащих руд производится открытым способом. При этом наблюдается распространение пыли, возникшей при введении взрывных работ и её осаждение на значительной территории, что обуславливает загрязнение почвы. Величина техногенного загрязнения зависит от мощности взрыва, глубины отрабатываемого карьера, направления и силы ветра, продолжительности эксплуатации карьера и других факторов.

Анализ состояния почв вокруг техногенного объекта показано на рис. 1. Частичное обогащение почв техногенными элементами проходило в начале деятельности карьера, когда глубина карьера составляла до 200 м. Когда проводились взрывные работы, твердые дисперсные частицы с поверхности карьера разносились вокруг карьера в зависимости от розы ветров. В дальнейшем, за счет углубления карьера, эффект загрязнения уменьшался и в настоящий момент (когда глубина карьера составляет более 600 м), рудные частицы, поднятые во время взрыва в воздух, выпадают обратно в карьер. В результате вокруг карьера загрязнение почв, грунта техногенными соединениями практически отсутствует.

Как видно из рис. 1. концентрации элементов (мышьяк и золота) на расстоянии от карьера уменьшаются, до 4 км и равняются Кларкам. Это означает, что на расстояние более 4 км воздействия техногенных объектов на экосистему максимально уменьшается. 


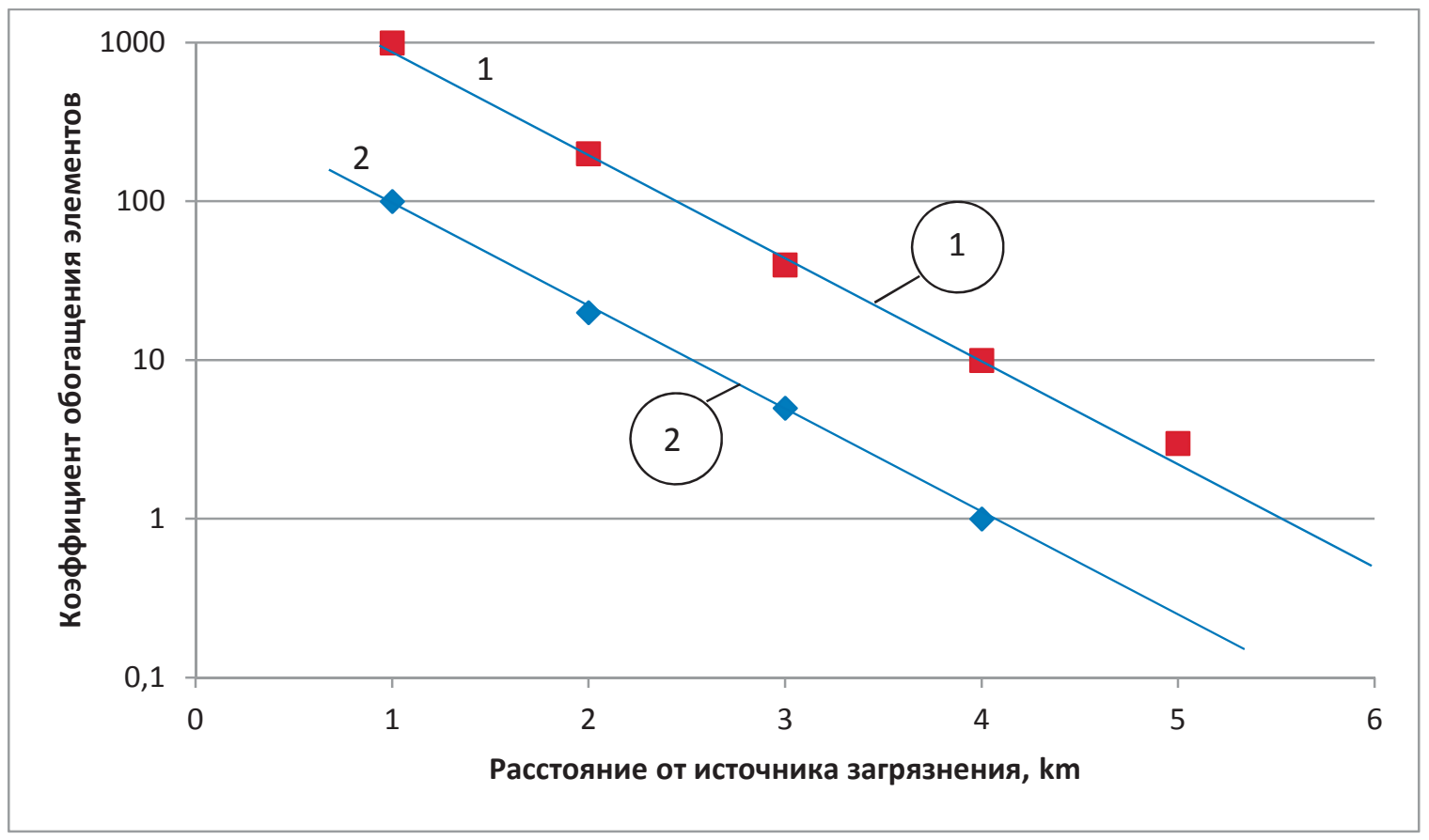

Рис. 1. Изменение средней концентрации техногенно-образованных элементов от расстояния до источника загрязнения:

1 - кривая $\mathrm{K}_{\text {об }}$ - мышьяка, 2 - кривая $\mathrm{K}_{\text {об }}$ - золота

Оценка техногенного влияния уранодобывающего производства на экосистему. В течении последних 10 лет мы проводили систематический контроль следующих вредных и радиационно-дозиметрических факторов:

- в почве: отобраны пробы почвы на глубине 0-0,5 м. на месте измерения мощности эквивалентной дозы гамма-излучения (МЭД), затем в лабораторных

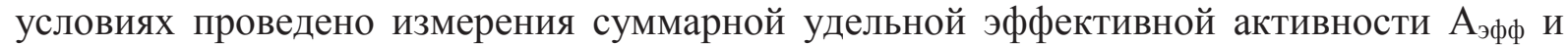
удельную активность естественных радионуклидов $\mathrm{K}^{40}, \mathrm{Ra}^{226}$, урана (природный), $\mathrm{Th}^{232}$ гамма-спектрометрическим методом.

- в воздухе: определена концентрация пыли весовым методом, $\mathrm{HCN}, \mathrm{NH}_{3}, \mathrm{NO}_{2}$, $\mathrm{SO}_{2}, \mathrm{H}_{2} \mathrm{~S}, \mathrm{H}_{2} \mathrm{SO}_{4}, \mathrm{~Pb}, \mathrm{P}_{2} \mathrm{O}_{5}$ фотоколориметрическим методом, объемной активности радона, тарона, мощности экспозиционной или эффективной дозы (МЭД) в рабочих помещениях и оборудованиях радиометрами СРП-68 или дозиметрами-радиометрами ДКС-96, определена объёмной активности радона (ОАР) в атмосферном воздухе населённых пунктов и в воздухе рабочей зоны в помещениях прибором ALPHAGUARD, определена эквивалентной равновесной объёмной активности дочерних продуктов распада радона (ЭРОА) в атмосферном воздухе населённых пунктов, в воздухе рабочей зоны и помещениях приборами «Поиск» и радон-WL-метр, долгоживущих альфа-нуклидов (ДАН) в атмосферном воздухе населённых пунктов, в воздухе рабочей зоны и в помещениях, с отбором проб на аспирационные фильтры, мощности гамма-излучения в непрерывном режиме для контроля выброса аэрозолей в атмосферу.

- в питьевых, подземных и производственных сточных водах: сухой остаток, взвешенные вещества, $\mathrm{pH}$, нефтепродукты, анионы - $\mathrm{Cl}^{-}, \mathrm{NO}_{2}^{-}, \mathrm{NO}_{3}{ }^{-}, \mathrm{CO}_{3}{ }^{-}, \mathrm{HCO}_{3}{ }^{-}, \mathrm{SO}_{4}^{-}$, катионы- $\mathrm{Ca}, \mathrm{Mg}$ - титраметрическим методом, $\mathrm{Si}^{+}, \mathrm{F}^{+}, \mathrm{As}^{+}, \mathrm{Mo}^{+}, \mathrm{Al}^{+}$ фотоколориметрическим методом, нитриты, K, Na, Feобщ, $\mathrm{Cu}, \mathrm{Mn}, \mathrm{Pb}, \mathrm{Co}, \mathrm{Ni}, \mathrm{Zn}, \mathrm{Cr}-$ атомно-абсорбционным методом, отбор проб воды и определение в них естественного 
урана, радия-226, полония-210, тория-232, радона - эманационным методом и суммарной альфа и бета активности на приборе УМФ-2000.

Кроме вышеперечисленных измерений немаловажную роль играет систематическое определение величины радиоэкологических факторов, связанных с деятельностью уранодобывающих предприятий, существенно влияющих на радиоэкологическую стабильность и чистоту окружающей среды, а именно: величина радиоактивных выбросов в атмосферу при прокалке готовой продукции урана.

Контроль за радиоэкологической обстановкой в урановом производстве. Объем выбрасываемого в атмосферу воздуха из вентиляционных систем цехов, перерабатывающих золотое и урановое сырье, может достигать 700 м³/мин. Особенно велика опасность загрязнения воздуха в отделениях дробления в случае добычи золота, а также в отделении затаривания и прокалки готовой продукции - в случае урана. Это требует применения самых эффективных инженерных решений для максимального предотвращения пылеобразования в рабочей атмосфере цехов и тем более во внешней среде.

Как известно, для оценки воздействия излучений радиоактивных веществ на здоровье работающего персонала и населения требуется систематический контроль в окружающей среде (атмосферном воздухе). Поскольку производство урана связано с переработкой радиоактивных материалов, это является наиболее важным и предопределяющим фактором.

Из спектра видно рис. 2, что значения удельной активности зависит от концентрации ${ }^{234} U$ в природной смеси изотопов. Дело в том, что изотоп ${ }^{234} U$ имеет высокую удельную активность - $\left(2,3^{*} 10^{8}\right.$ Бк/г), в то время как удельная активность природной смеси урана составляет всего $2,5 * 10^{4}$ Бк/г. Следовательно, такая разница в удельной активности может быть объяснена нарушением изотопного равновесия урана за счёт увеличения доли изотопа ${ }^{234} \mathrm{U}$. Это факт подтвердилось результатами наших исследований.

Известно, что ПДК урана в воздухе рабочей зоны составляет 0,088 мг/м², в промышленных газовых выбросах ПДВ - 6,0 мг/с. Крупнодисперсные частицы менее подвижны, чем мелкодисперсные. В связи с этим, представляет интерес ликвидация попадания мелкодисперсных частиц (аэрозолей) в окружающую среду, так как время их нахождения в воздухе наиболее длительное.

Использование ядерных фильтров, изготовленных в объединенном институте ядерных исследований (Россия, г. Дубна) с крупностью пор 0,7-4,0 мкм в сочетании с традиционными фильтрами позволило разработать оригинальную методику определения фракционного состава радиоактивного аэрозоля в воздухе в зависимости от климатических условий и фактических условий в производстве. Использование разработанной методики радиоэкологического контроля производства позволило определить механизм нарушений коэффициента радиоактивного равновесия между изотопами урана.

Для определения достоверности результатов, анализа изотопного состава урана с использованием альфа - спектрометрических анализаторов типа - “Ortec”, Analyst” и “Прогресс-Альфа” сравнивали с данными масс-спектрометрического (МС) анализа. Установлено допустимое расхождение между методами анализа.

Из проведенных многолетних исследований по оценке влияние добычи золота и урана на экосистему можно сделать вывод, что вокруг техногенных объектах почва 
частично обогащены техногенными элементами. На данный момент это процесс практически отсутствует.

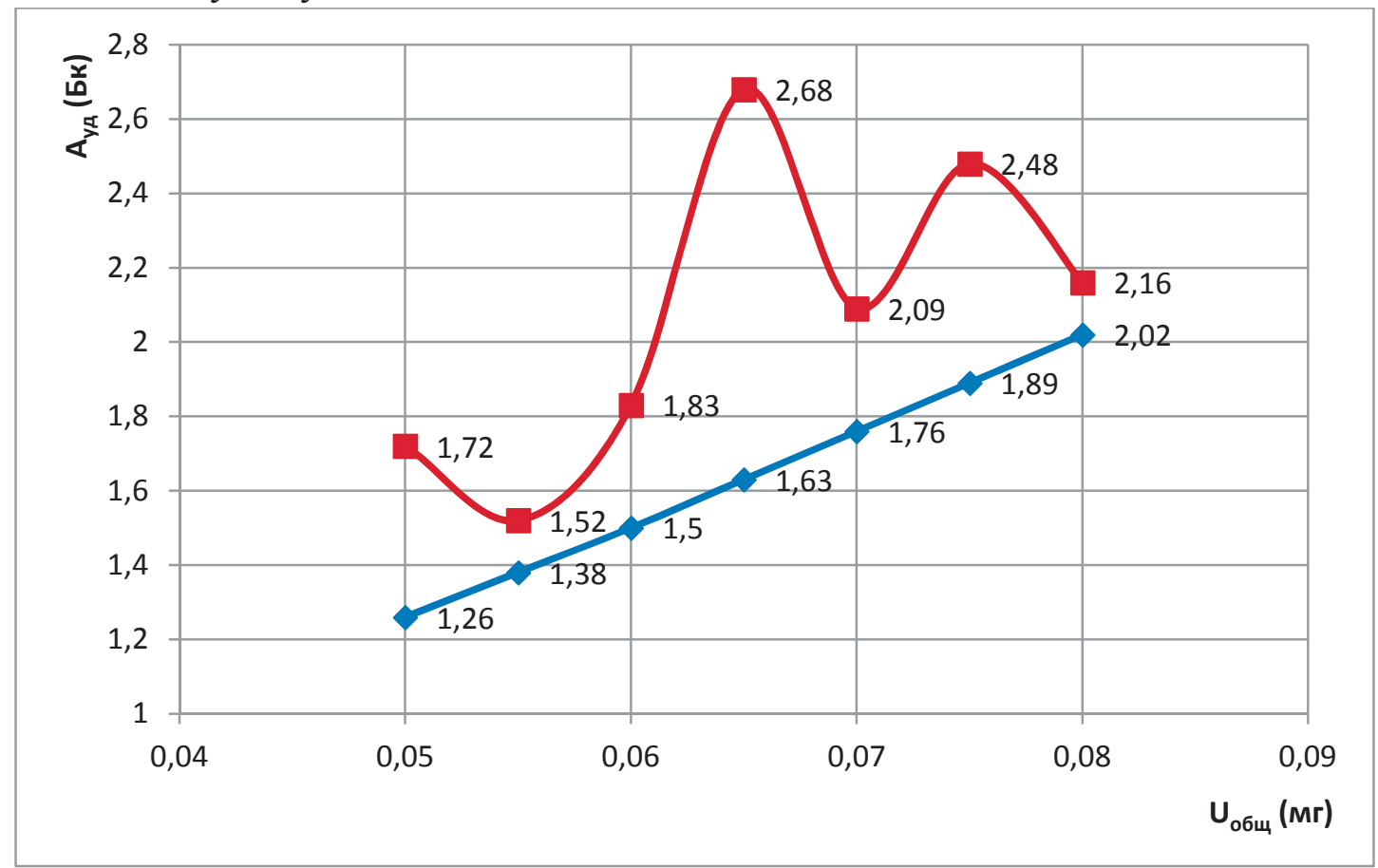

Рис. 2. Зависимость удельной активности воздуха от концентрации урана:

1-нижняя линия зависимость удельной активности воздуха от концентрации урана при радиоактивном равновесие изотопов урана, 2-верхняя линия зависимость удельной активности воздуха от концентрации урана при нарушений радиоактивного равновесия изотопов урана

Концентрации вредных и радиационно-дозиметрических ингредиентов вокруг техногенных объектах соответствует установленным нормам и не превышает значений, установленных в СанПиН-0193-06.

\section{Список литературы:} $240 \mathrm{c}$

1. Пивоваров Ю.П., Михалев В.П. Радиационная экология. -М.: Академия, 2004. -

2. Бекман И. Радиоактивность, радионуклиды и радиация. - M.: PALMARIUM, 2014. - 498 c.

3. Музафаров А.М., Темиров Б.Р., Саттаров Г.С. Оценка влияния техногенных факторов на экологию региона. Горный журнал. М., 2013. №8.(1). - С.65-68.

4. Музафаров А.М., Темиров Б.Р., Саттаров Г.С. Экологических мониторинг техногенных факторов при добыче и переработке урана и золота. Экологический вестник, 2013. №12.(152). - С.24-33.

5. Музафаров А.М., Саттаров Г.С., Ослоповский С.А. Радиометрические исследования техногенных объектов. «Цветные металлы». М., 2016. №2. - С. 15-18.

6. Нормы радиационной безопасности (НРБ-2006) и основные санитарные правила обеспечения радиационной безопасности (ОСПОРБ-2006). - Ташкент, 2006. - 136 с. 